\title{
Da Fundação do Hospital das Clínicas à Criação da Unidade de Emergência e sua Transformação em Modelo Nacional de Atenção Hospitalar às Urgências
}

\author{
José Sebastião dos Santos \\ Coordenador das Atividades Administrativas da Unidade de Emergência. \\ 1999 - 2002
}

\section{A FUNDAÇÃO DO HOSPITAL DAS CLÍ- NICAS}

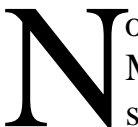
o início das atividades da Faculdade de
Medicina de Ribeirão Preto da Univer-
sidade de São Paulo (FMRP-USP), as práticas clínicas eram desenvolvidas, com limitações, nos pavilhões da Santa Casa de Misericórdia local. A conjunção de forças advindas da mobilização dos estudantes, da disposição dos professores e da vontade da sociedade local, abriram caminho para a conquista do primeiro estabelecimento hospitalar, vinculado às recém criadas Faculdade de Medicina e Escola de Enfermagem de Ribeirão Preto da Universidade de São Paulo.

Naquela época, a Fundação Sinhá Junqueira estava construindo uma Maternidade à Rua Bernardino de Campos. O prédio tinha 4 andares e capacidade para 150 leitos. As obras estavam em andamento, quando foi aventada a possibilidade de entregar o prédio, em regime de comodato, ao Estado de São Paulo, para que ali fosse instalado o Hospital das Clínicas da Faculdade de Medicina de Ribeirão Preto da Universidade de São Paulo (HCFMRP-USP).

O convênio assinado entre a Universidade de São Paulo e a Fundação Sinhá Junqueira, no dia 09 de abril de 1953, foi o marco inicial da história do HCFMRP-USP (Figura 1). O documento formalizou a cessão por 20 anos de um prédio ainda inacabado, onde posteriormente seria instalado o primeiro Hospital-Escola do Interior do País.

Acertado o convênio, o Prof. Dr. Zeferino Vaz deu início ao plano de conclusão da maternidade com as modificações que as necessidade didáticas e assistenciais vieram a exigir. Além do Prof. Dr. Zeferino Vaz, os grandes apoiadores desse processo foram os Drs. Waldemar Barnsley Pessoa, Presidente da Fundação Sinhá Junqueira, e o Dr. Paulo Gomes Romeo, Presidente do Centro Médico local e que, mais tarde, viria a ser o primeiro Superintendente do HCFMRPUSP.

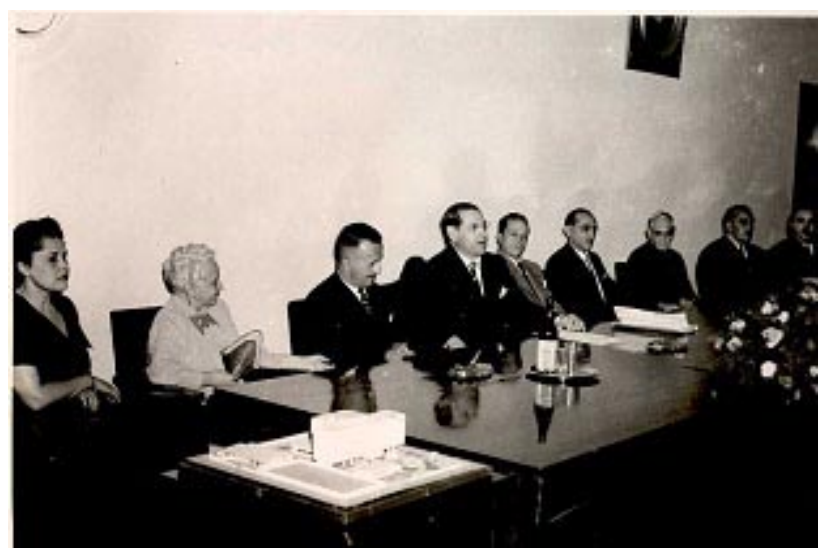

Figura 1 - Cerimônia de assinatura do convênio com a Fundação Sinhá Junqueira para instalação do Hospital das Clínicas, em 9 de abril de 1953. 
A obra foi finalizada com recursos do Governo do Estado de São Paulo. No ato da solenidade de criação do Hospital das Clínicas, em 11 de novembro de 1954, estiveram presentes o Governador, Lucas Nogueira Garcez, o Dr. Altino Arantes, Ex-Governador de São Paulo, o Prof. Dr. Melo Moraes, Reitor da USP, a D. Sinhá Junqueira, o Prof. Dr. Zeferino Vaz, Diretor da FMRP-USP e outras autoridades civis, militares e religiosas.

Os estudantes da $1^{\text {a }}$. turma da Faculdade de Medicina estavam cursando o $5^{\circ}$ ano médico, quando, em 31 de julho de 1956, foram iniciadas as atividades do Hospital das Clínicas. (Figura 2). Mais tarde, quando do término do comodato, o prédio viria a ser desapropriado pelo Estado de São Paulo, para dar lugar à atual Unidade de Emergência.

O prédio localizado na Rua Bernardino de Campos, na região central da cidade, até hoje mantém a sua originalidade, com 5 pavimentos.

Quando foi inaugurado, contava ainda com 5 edículas auxiliares, que abrigavam os ambulatórios, a cirurgia experimental, a casa de força e o almoxarifado. De acordo com o projeto inicial, o hospital foi concebido para funcionar da seguinte forma:

- andar térreo: serviços gerais e administração, cozinha, rouparia, farmácia, sala de aula, equipamentos de raio- $X$, craneógrafo e angiocardiógrafo e uma mesa urológica.
- $1^{\circ}$ andar: banco de sangue, laboratório de análise clínicas, sala da Escola de Enfermagem, salas para estudantes, acomodações dos médicos internos e consultórios.

- $2^{\circ}$ andar: Clínica Médica, que contava com 10 enfermarias e salas de professores, biblioteca, e serviço de Radioscopia.

- $3^{\circ}$ andar: Clínica Cirúrgica, com 3 salas de operações, salas de Anatomia Patológica, sala de revelação de angiografias, material anestésico, seção de esterilização, 8 enfermarias e 2 centros de recuperação.

- $4^{\circ}$ andar: Clínicas Ginecológica e Obstétrica e Pediatria, com 9 enfermarias, 2 berçários, consultório de puericultura, lactário, sala de preparo de parto, sala de recepção do recém-nascido e 2 salas de parto.

O primeiro ambulatório do Hospital das Clínicas de Ribeirão Preto a entrar em funcionamento foi o de Clínica Ginecológica e Obstétrica. Com a Clínica Cirúrgica já em atividade (Figura 3), em agosto de 1956, acontece a primeira intervenção cirúrgica do Hospital das Clínicas. Foi uma Gastrectomia realizada com sucesso pela equipe do Prof. Dr. Ruy Ferreira Santos.

Não precisou de muito tempo para que o Hospital das Clínicas se tornasse o principal centro de assistência e de ensino médico do Interior do Estado. De acordo com registros oficiais da época, só nos 4 primeiros meses de atividade, foram contabilizados 2.942 atendimentos, sendo 1.393 consultas, 1.549 retornos e

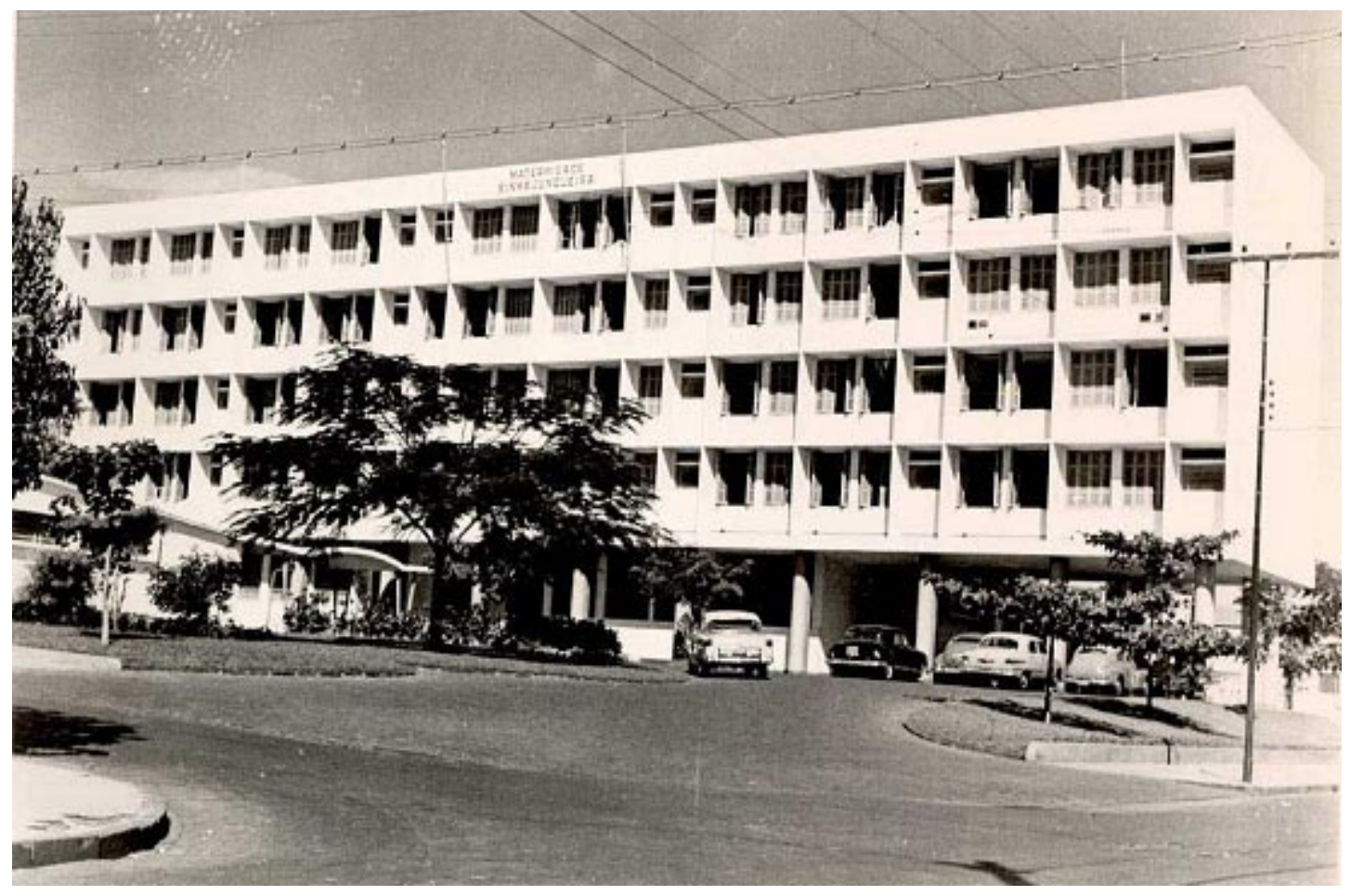

Figura 2 - Fachada do Hospital das Clínicas (1956). 


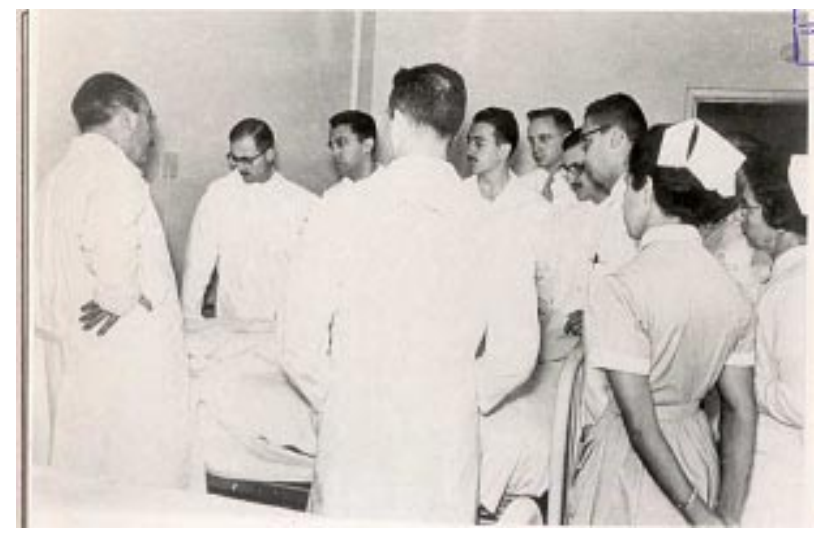

Figura 3 - Primeira visita coletiva à enfermaria de cirurgia, em 31 de julho de 1956.

445 pacientes internados. Também foram registrados 110 nascimentos, 550 exames radiológicos, 4.354 exames de laboratórios e 253 cirurgias. Dos pacientes atendidos, a maioria pertencia a Ribeirão Preto, mas, também, já eram assistidos doentes de cerca de 69 cidades do Estados de São Paulo, Minas Gerais e Goiás.

Com a demanda de pacientes aumentando a cada dia e a necessidade da instalação de novas clínicas, a ampliação do hospital passa a ser inevitável. As negociações para captação de recursos se concretizam, e, em dezembro de 1956, inicia-se a obra de construção da fundação e dos alicerces de um prédio anexo (atual Bloco B), concluído em 1957. A obra consumiu cerca de 54 milhões de cruzeiros. Os recursos foram disponibilizados durante os mandatos do Governadores Jânio Quadros e Carvalho Pinto. O novo prédio foi equipado com sistema de ar refrigerado, central de distribuição de oxigênio e salas de cirurgia.

A boa condição assistencial do Hospital das Clínicas e o espírito de investigação científica dos Departamentos da FMRP-USP favoreceram os avanços obtidos na compreensão da fisiopatologia e no desenvolvimento de recursos diagnósticos e terapêuticos para as sequielas da Moléstia de Chagas. A sensibilidade para colaborar com o enfrentamento de uma endemia nacional e com grandes repercussões regionais deu visibilidade e credibilidade às duas novas instituições.

Os rumos do Hospital das Clínicas começaram a mudar com a assinatura de um contrato para planejamento e construção de uma sede própria no Bairro Monte Alegre. As atenções passaram a ficar centradas na construção da nova unidade. A estrutura do prédio chegou a ser erguida, mas, por falta de verbas do Governo Estadual, a obra foi interrompida. Só depois de um levantamento técnico e quase 7 anos mais tarde, a obra foi retomada.
Expirado o convênio entre a Fundação Sinhá Junqueira e a Faculdade de Medicina, o então superintendente do Hospital, Prof.Dr. Carlos Eduardo Martinelli, solicitou ao reitor da USP autorização e a respectiva disposição orçamentária para a aquisição do Prédio da Maternidade Sinhá Junqueira.

Nesse período, foi criado um local para o atendimento a pacientes portadores de queimaduras e 1 sala do hospital foi adaptada para atendimento de urgência. Esses talvez, tenham sido os primeiros passos para a implantação de uma Unidade de Emergência na cidade. Tal iniciativa facilitou o contato dos estudantes de Medicina com a rotina dos procedimentos de urgência, já que, até então, eles tinham que se deslocar até São Paulo para terem a prática da disciplina. Inicialmente, apenas pacientes de Ribeirão Preto eram atendidos, mas, aos poucos, praticamente toda a região passou a buscar atendimento de urgência no Hospital das Clínicas.

O Governo do Estado declara o imóvel, onde funciona o Hospital das Clínicas, como prédio de utilidade pública e, em julho de 1976, inicia-se o processo de desapropriação do mesmo. Paralelamente, a própria direção do Hospital das Clínicas realiza um estudo preliminar para transformar em definitivo o antigo hospital em Unidade de Emergência. Todavia a concretização de fato e a implantação inicial de um serviço de Pronto-Socorro só foi efetivada, quando a Unidade do Monte Alegre entrou em funcionamento, em 1978, e os primeiros pacientes começaram a ser transferidos para o novo hospital, no Campus da USP. O Prof. Martinelli, que esteve na administração de dezembro de 1971 a maio de 1983, foi o responsável pelo desenvolvimento dos procedimentos que colocaram em funcionamento o Hospital das Clínicas, no Bairro Monte Alegre.

\section{A CRIAÇÃO DA UNIDADE DE EMERGÊN- CIA}

Os primeiros registros historiográficos sobre a denominação Unidade de Emergência (UE) surgem a partir do início das obras no pavimento térreo e no $1^{\circ}$ andar do hospital, que já estava sendo preparado para abrigar os serviços de urgência.

No ano de 1981, o HCFMRP-USP comemorou seu Jubileu de Prata. Durante a solenidade, foi prestada uma homenagem ao Dr. Waldemar Barnsley Pessoa e o anfiteatro do hospital recebe o nome do médico que colaborou ativamente no processo de cessão do prédio da Fundação Maternidade Sinhá Junqueira.

No mês de abril de 1982, a Unidade de Emergência é oficialmente inaugurada. Com acesso pela rua 
Quintino Bocaiúva, passa a funcionar um ambulatório com atendimento durante 24 horas. Pouco tempo depois, entra em funcionamento o centro especializado para tratamento de pessoas vítimas de queimaduras. A nova Unidade de Queimados, instalada no $4^{\circ}$ andar do prédio da UE, vem suprir uma antiga necessidade, já que, até então, os pacientes da região tinham que ser encaminhados para hospitais de São Paulo e Rio de Janeiro.

Apesar de todo o esforço, a demanda excessiva para assistência passa a ser o principal problema da UE. Durante a gestão da Superintendente Profa Dra Marisa Mazzoncini de Azevedo Marques (período de maio de 1983 a maio de 1987) ocorre a ampliação do prédio. Foi durante essa administração que, pela primeira vez, foi indicado pela Superintendência um docente como responsável efetivo pela UE. O Prof. Dr. Albert Amin Sader assumiu o cargo de Diretor das Atividades Administrativas da UE em junho de 1983, e permaneceu na função por quase 10 anos.

Nesse período, a área do antigo Serviço de $\mathrm{Nu}-$ trição, onde funcionava a cozinha e o refeitório de médicos e funcionários, é transformada em recepção e acomodação de pacientes com quadro clínico de baixa complexidade. Essa ampliação da capacidade exigiu a construção de nova área para o Serviço de Nutrição, que passou a ocupar o espaço onde, inicialmente, ficavam os tanques de oxigênio e nitrogênio, deslocados para outro ponto.

Com a implantação dos serviços de ProntoAtendimento de Clínica Médica, Neurologia e Cirurgia, nessa área reformada, e a facilidade de acesso ao Banco de Sangue e a Radiologia, todos localizados no térreo, as atividades assistenciais tornaram-se mais ágeis. Essas modificações exigiram uma nova porta de entrada para os pacientes, ainda funcionando pela Rua Quintino Bocaiúva, que, muitas vezes, ficava bloqueada pelo fluxo de veículos que circulavam pelos bares da moda, localizados naquela região. A solução foi a construção de uma marquise, na antiga entrada da maternidade, e uma pista asfaltada para que o acesso de pacientes e ambulâncias viesse a ser realizado pela Rua Bernardino de Campos. Com modificações estruturais e funcionais, a recepção ainda mantém as caracterísitcas daquela inaugurada em fevereiro de 1987 (Figura 4), quando a UE passou a contar, também, com os serviços de controle de leitos e triagem médica, de 8 até as 22 horas, todos os dias.

Nessa gestão, houve a ativação gradativa de novas vagas para pacientes. Todavia, o atendimento era realizado por médicos residentes e acadêmicos, pois os docentes dos diferentes departamentos não atuavam durante o dia, na UE. Depois de acatada pela Direto- ria da Faculdade de Medicina uma reivindicação do Prof. Sader, a Universidade de São Paulo autorizou a contratação de 5 professores para atuar junto à UE. Com a execução de algumas reformas estruturais, houve a disponibilização de área próxima ao Serviço de Radiologia para atendimento inicial de pacientes politraumatizados e com urgências clínicas graves.

A demanda crescente de pacientes vítimas de intoxicações exógenas e envenenamentos causados por animais peçonhentos, motivou a solicitação feita pelo Prof. Dr. Hélio Lourenço de Oliveira, Chefe do Departamento de Clínica Médica, à Superintendência, para que fosse instalado, no HCFMRP-USP, um Centro para o Controle das Intoxicações, nos moldes dos já existentes no país. Os trâmites iniciais a partir de 1983, levaram a Coordenadoria de Serviços Técnicos Especializados da Secretaria de Saúde do Estado de São Paulo a ceder um sistema de leitora e microfichas específicas para a orientação no atendimento dessas afecções. A chegada desse sistema e sua instalação na UE, em abril de 1983, deu início às atividades do Centro de Controle de Intoxicações (CCI), oficialmente inaugurado em março de 1984, quando, seguindo as normas nacionais exigidas, o centro já contava com um Laboratório de Toxicologia e um ramal telefônico, funcionante nas 24 horas.

O conjunto de atividades de assistência médica e informativa para os casos clínicos, desde essa época, é realizado por acadêmicos de Medicina do $4^{\circ}$ e do $6^{\circ}$ ano, supervisionados por médicos assistentes do Hospital das Clínicas e docentes dos Departamentos de Clínica Médica e Pediatria da FMRP-USP. Recentemente, a ocupação racional dos espaços físicos tem permitido a ampliação de exames toxicológicos pelo laboratório. A informatização, por meio de programas internacionais, destinados à orientação das condutas médicas, mantém o CCI como Referência Nacional para a assistência às intoxicações, envenenamentos e aplicação de soros antivenenos. Levantamento estatístico, realizado entre o ano de 1995 e 2000, demonstra um atendimento médio anual de aproximadamente 2.000 pacientes.

O período de maior turbulência do HCFMRPUSP foi na gestão do superintendente Prof. Dr. Antonio Carlos Pereira Martins, que assumiu o cargo em maio de 1987 e permaneceu nele até março de 1995. O país vivia um momento de crise econômica e inflação alta. Nessa época, o HCFMRP-USP, após muitas discussões, passa a integrar, oficialmente, o Sistema Único de Saúde. A UE recebeu, nesse período, nova área de acesso de pacientes que podiam aguardar o atendimento em sala de espera mais ampla. 
No ano de 1993, a UE passa a ser dirigida pelo Prof. Dr. José Ivan de Andrade. Com a proliferação dos casos da Síndrome da Imunodeficiência Adquirida (SIDA), o hospital entra em sua fase mais crítica. A demanda ultrapassa os limites da capacidade instalada, causando problemas de superlotação. A taxa de ocupação na UE ultrapassa $120 \%$. Pacientes, encaminhados de outros hospitais da Região e até de outros Estados, e mais os da própria cidade, se espremiam nas enfermarias, ambulatórios e corredores do hospital.

A falta de recursos humanos e infra-estrutura fizeram cair a qualidade do atendimento. Os médicos trabalhavam num clima de insegurança e, muitas vezes, sob pressão. Em diversas ocasiões, segundo o Prof. Andrade, o corpo clínico do Hospital das Clínicas se deparou com o dilema ético, de escolher qual seria o paciente a ser atendido primeiro e qual deles poderia suportar um pouco mais a dor. O ex-dirigente conta, ainda, que, em alguns casos, teve que tomar medidas drásticas, para tentar diminuir o fluxo de pacientes. Em diversas situações, mandou de volta os doentes que não apresentavam um quadro clínico de maior gravidade e até chegou a denunciar colegas ao Conselho Regional de Medicina por encaminhamento indevido de pacientes.

As dificuldades encontradas nesse período não foram superadas da noite para o dia. As ações administrativas acabaram tendo efeito gradativo. Com a implantação da Unidade Especial de Tratamento de Doenças Infecciosas (UETDI), em 17 de junho de 1996, os pacientes com SIDA passaram a ter seguimento e atendimento na nova área do Hospital Campus. Outra medida para tentar diminuir o número de pacientes internados na UE foi o processo de desenvolvimento das centrais de controle de vagas. As primeiras unidades a operar com o programa de distribuição de casos foram a Psiquiatria e a Obstetrícia, no ano de 1991.

Nesse período, foi criada a Fundação de Apoio ao Ensino, Pesquisa e Assistência (FAEPA), com a finalidade de obter receita adicional e administrar os recursos arrecadados pelo hospital. A FAEPA foi instituída oficialmente em 31 de agosto de 1988. Os recursos gerados pelo Hospital das Clínicas e administrados pela FAEPA permitiam investimentos em pessoal, na manutenção básica do hospital, no aprimoramento da estrutura física e na atualização de equipamentos médicos para diagnóstico e terapêutica. O Prof. Dr. Martins deixou a Superintendência do HCFMRPUSP em 1995, quando, então, assumiu o atual superintendente, o Prof. Dr. Marcos Felipe Silva de Sá.
A partir de 1995, com o apoio da FAEPA, a Administração do HCFMRP-USP reforça a atenção dispensada à UE. Na época, as condições de trabalho ali existentes comprometiam seriamente a qualidade do atendimento, assim como tornavam os servidores extremamente desmotivados. Havia deterioração do próprio prédio e sucateamento de seus equipamentos.

A UE era vítima do velho modelo de atenção à saúde, com assistência centrada nos serviços hospitalares, bem como da falta de organização do Sistema Único de Saúde (SUS), então recém-criado e com carência de recursos.

Era necessário redefinir o papel da UE, tendo em vista a sua importância para a Região, bem como por ela se constituir a linha de frente na interface entre a Faculdade de Medicina, através do seu Hospital das Clínicas, e a Comunidade. A exposição negativa era tão forte que colocava em risco o próprio prestígio do Hospital das Clínicas e da Universidade, a ponto de suscitar, internamente, discussões sobre a conveniência da permanência dos Departamentos da FMRP-USP na UE.

Com a implantação do Projeto Reforsus, em 1996, pelo Governo Federal, vislumbrou-se a oportunidade de serem feitos os investimentos necessários para readequar a UE, tanto no que diz respeito a equipamentos como a áreas físicas e às suas reais finalidades. Os recursos do Reforsus resultaram de acordo entre o Banco Interamericano de Desenvolvimento e o Banco Mundial. O Projeto Reforsus tinha, como metas, o fortalecimento da rede de saúde, com financiamento de projetos para a recuperação física, tecnológica, gerencial e operacional das Unidades de Saúde, visando à ampliação do acesso da população brasileira aos serviços.

Com apoio dos 25 Secretários Municipais de Saúde da Região, conseguiu-se a adequação do pleito, junto ao Projeto Reforsus, para a UE.

A administração do Prof. Andrade durou até 1999. Com ele, foram dados os primeiros passos para a modernização da estrutura física. Em maio de 1999, assume a Coordenação das Atividades Administrativas o Prof. Dr. José Sebastião dos Santos. O projeto de restauração física e de sintonia com a Política Pública de Saúde é fortalecido com os investimentos recebidos. Entre 1996 e 2002, a UE é contemplada com R\$ 9.492.646,00 pelo Projeto Reforsus, com contrapartida de 18,3\% deste total pelo Estado de São Paulo. A FAEPA participou com R\$7.601.016,00 em obras e equipamentos não supridos pelo Reforsus. A UE é restaurada e modifica seu modelo de gestão e de assistência. (Figura 5) 


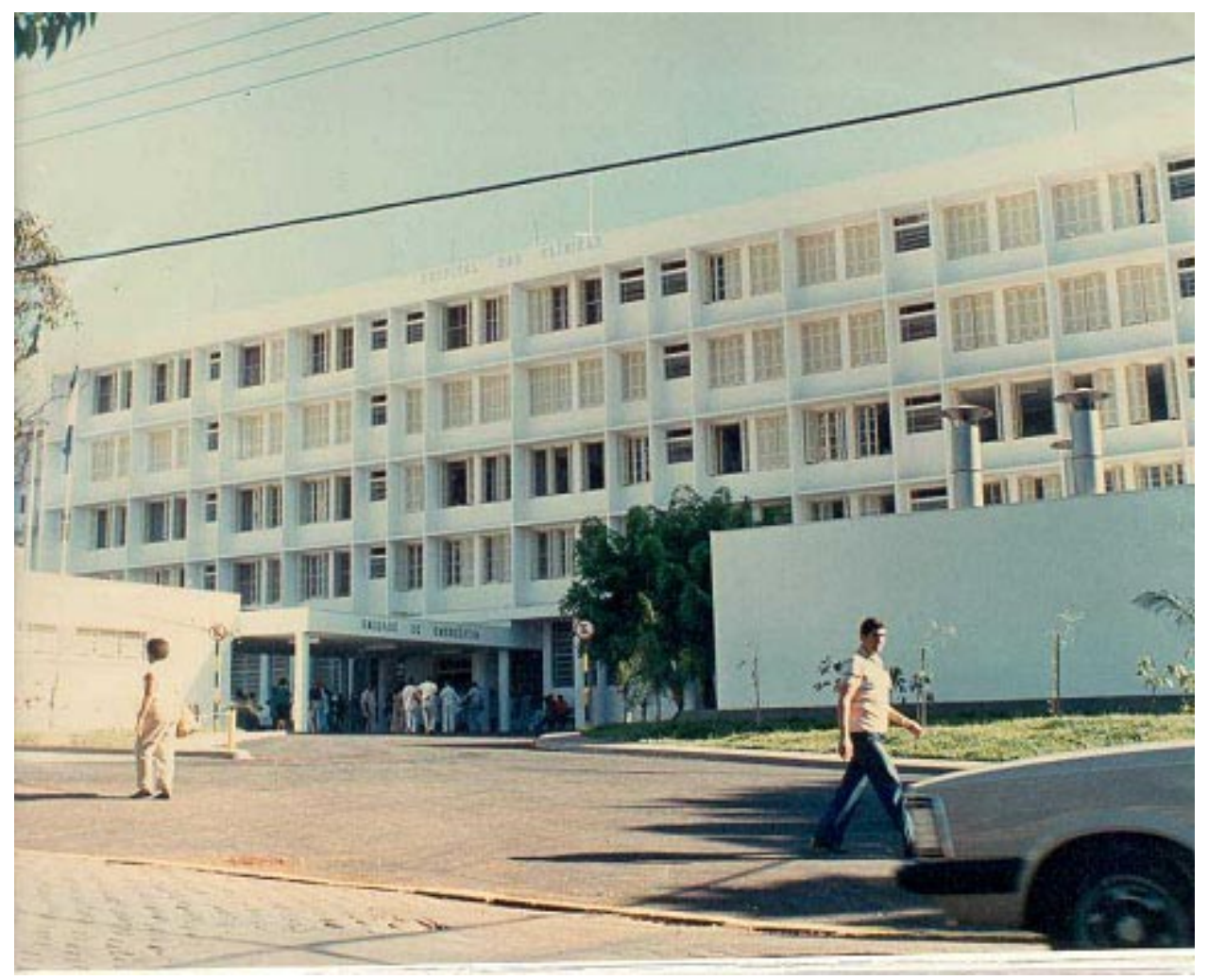

Figura 4 - Fachada da Unidade de Emergência do Hospital das Clínicas após construção da marquise e do Serviço de Nutrição (1987)

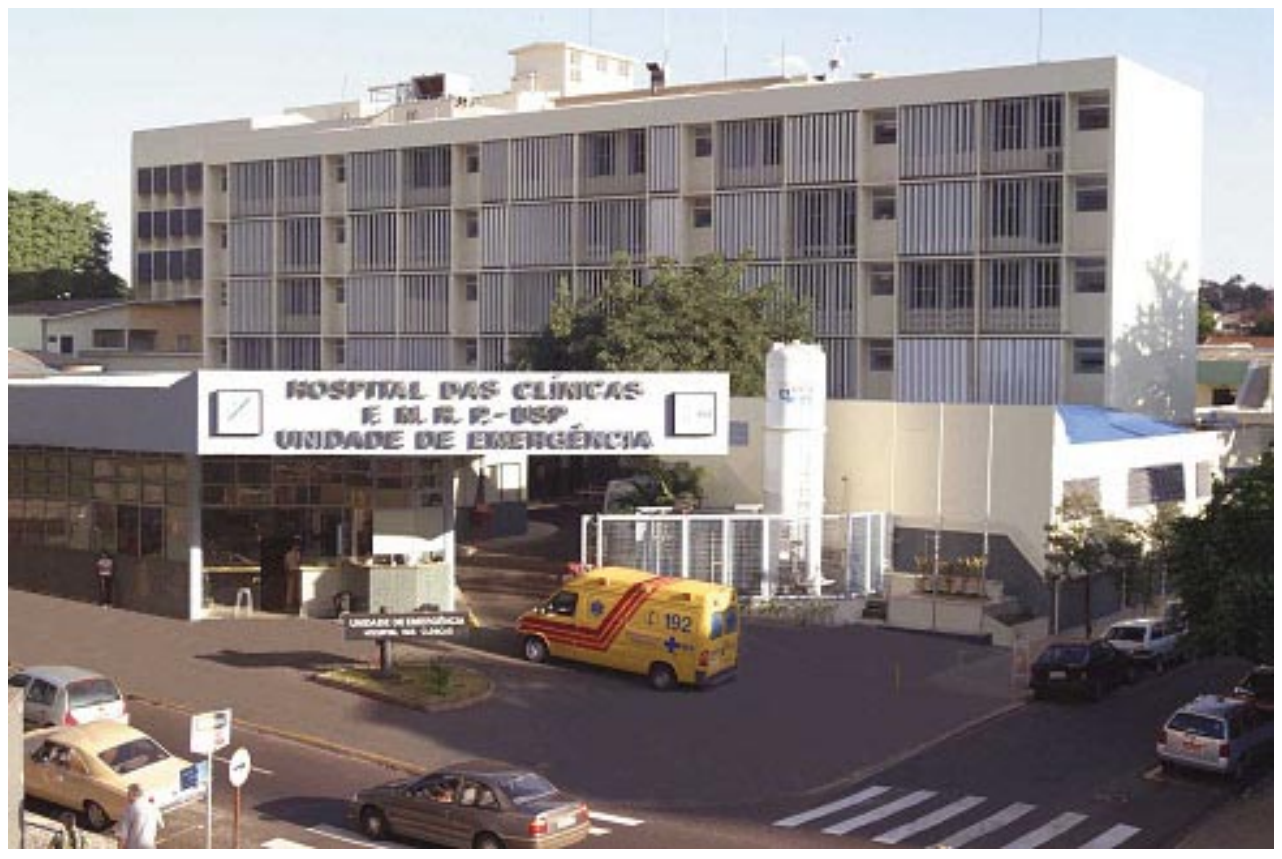

Figura 5 - Fachada da Unidade de Emergência (2002). 
A interdependência administrativa da UE em relação ao Hospital Campus foi minimizada, com a descentralização da estrutura administrativa, mediante a implantação da gestão compartilhada, centrada no planejamento e na execução colegiada.

A parceria com a Secretaria Municipal de Saúde e a DIR XVIII para implantação da Central Única de Regulação Médica (CURM), construída no $2^{\circ}$ semestre de 1999, permitiu, paulatinamente, a organização do fluxo de pacientes, com redução progressiva das taxas de ocupação de leitos a níveis eticamente aceitáveis. Restringiram-se as consultas aos casos com real necessidade, o que traduziu em melhoria sensível na qualidade do atendimento.

Grande ênfase foi dada aos aspectos da humanização do atendimento, a começar pelo acolhimento dos pacientes. As visitas passaram a ser diárias e ao longo do dia, com permissão para acompanhantes, mesmo nas salas de atendimento.

Houve um grande esforço para adequar a UE às novas necessidades. De 15 leitos existentes para pacientes críticos, em 1999, passou-se para 34 no ano de 2000 , o que representa um incremento de mais de $100 \%$.

Face às necessidades epidemiológicas, houve redefinição de ocupação das áreas com adequação física para implantação de 10 leitos para cuidados semiintensivos, destinados a pacientes com afecções clínicas, neurológicas e cirúrgicas. Finalmente, atendendo às necessidades de acolhimento para as afecções infectocontagiosas foram destinados 10 leitos de isolamento para os doentes clínicos, neurológicos e cirúrgicos.

Em consideração às atividades acadêmicas, foram reformados os 3 anfiteatros da UE (Figura 6), hoje dotados de todos os modernos recursos audiovisuais.

Foi criado o Centro de Estudos em Emergências com o objetivo de apoiar as atividades do ensino (Figura 7), de estimular o desenvolvimento da especialização em emergências médicas e de alavancar os projetos de pesquisa na área.

\section{A REFORMA ADMINISTRATIVA}

A reforma administrativa na UE pode ser vista como um processo de desacumulação de valores da cultura organizacional, motivada pelo esgotamento do sistema administrativo, vigente nas últimas décadas. Esse movimento transferiu valores da gerência científica, principalmente, no que se refere à verticalização da estrutura organizacional e da lógica de dominação - subordinação, para uma perspectiva de gestão colegiada, sustentada no intercâmbio de idéias múltiplas, com inclusão da racionalidade de quem executa os processos.

Essa postura administrativa requereu a construção de uma topografia organizacional mais horizontalizada e com novas formas de relações institucionais. Assim, a UE foi segmentada em 13 Unidades Funcionais, que dispõem de serviços claramente definidos e diretrizes básicas de funcionamento.

Cada unidade funcional possui uma equipe de gestão, que congrega todos os profissionais que prestam serviços naquela área de trabalho, os quais, em conjunto, gozam de autonomia no que tange à apreciação e redefinição do modelo técnico, gerencial e assistencial. Portanto, todos podem e devem participar da formulação das diretrizes e do planejamento do processo de trabalho, recriando os modos de atuação profissional e de organização da prestação de serviços, revitalizando os padrões de responsabilidade para com a assistência aos usuários.

Da equipe de gestão emana a escolha de um grupo gestor, composto por representantes de cada categoria profissional, escolhidos entre os pares, com mandato de 2 anos. Ao grupo compete a gestão administrativa e assistencial da Unidade Funcional com medidas necessárias à implementação dos planos de atuação, delineados em consonância com as políticas geradas pela Coordenação do Hospital.

Para melhor funcionalidade, cada Grupo Gestor elege um gestor, que tem o papel de animador e coordenador da equipe de gestão, sendo o gerente estratégico no monitoramento da execução dos planos delineados para a Unidade Funcional.

O Conselho de Gestores congrega os eleitos, a fim de processar às demandas de interface e interdependência das diferentes Unidades Funcionais, fortalecendo a idéia de rede institucional.

Essa estrutura organizacional, alocada nos espaços de produção de serviços, conta com o apoio de uma equipe de supervisores e responsáveis técnicos para cada categoria profissional. No âmbito particular de cada categoria profissional, cada supervisor ou responsável técnico desempenha o papel de apoiador, instrumentalizando as práticas de atenção hospitalar e abastecendo suas equipes com orientações e ações de regulação do exercício profissional.

Na estrutura organizacional, o Coordenador está apoiado pela Equipe de Planejamento e pelo Conselho Multiprofissional e Multidisciplinar. (Organograma abaixo) Os colegiados, mediante análise da conjuntura interna e externa das políticas de saúde e de forma- 
ção de profissionais para o setor, auxiliam na instituição e na implementação de diretrizes gerais de atenção hospitalar às urgências, articuladas com a rede de serviços do SUS.

Em síntese, a Gestão Colegiada abriu espaço para as distintas racionalidades, incluindo as dimensões afetivas e os mecanismos de identificação e participação do conjunto de profissionais, os quais acabam por modular as ações técnicas, pertinentes ao modelo assistencial.

\section{A ORDENAÇÃO DO ACESSO À REDE AS- SISTENCIAL DE URGÊNCIA PELA RE- GULAÇÃO MÉDICA E O IMPACTO NAS ATIVIDADES DA UNIDADE DE EMER- GÊNCIA}

Na história recente do Sistema de Saúde Brasileiro, o descompasso entre a conquista de direitos pela população e a falta de condições para garantí-los podem ajudar na compreensão das disfunções dos serviços de urgência.

De acordo com a Constituição Federal Brasi- leira, de 1988, a saúde é um direito social do cidadão, garantido por meio de esforço conjunto da União, dos Estados e dos Municípios. Com base em tal direito, em 1990, o SUS foi instituído com garantia dos princípios do cuidado universal, integral e da eqüidade de acesso aos serviços de saúde. Ainda foi prevista a construção de um modelo de atenção à saúde, com serviços públicos e ações integradas a uma rede regionalizada e hierarquizada, com base na complexidade das atividades assistenciais.

Apesar das conquistas social e política, garantidas pela Constituição, os Gestores do SUS, dos Serviços Assistenciais e das Escolas de Saúde não foram capazes de pactuar a introdução de mudanças fundamentais no modelo de atenção à saúde e de formação dos seus profissionais.

As atividades assistenciais e educacionais continuaram centradas nos hospitais que, providos de recursos tecnológicos e de profissionais especializados garantem o primeiro atendimento de pacientes portadores de doenças agudas, em todos os níveis de complexidade. Assim, a falta de pactuação de uma rede assistencial, de complexidade crescente, o controle

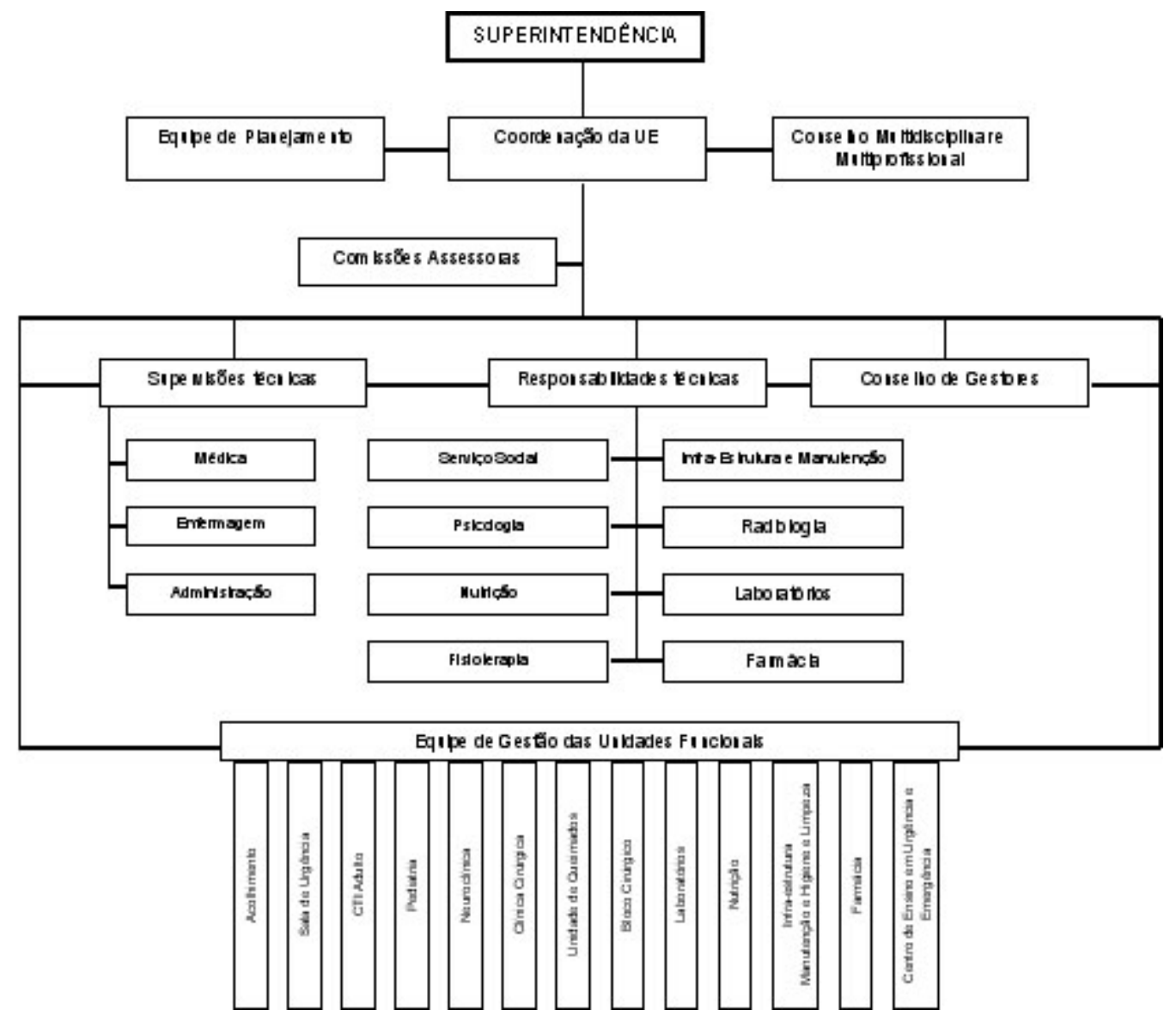

Organograma Administrativo da Unidade de Emergência. 
insuficiente dos fatores de risco à saúde individual e coletiva e o baixo rendimento dos serviços de atenção primária são, dentre outras, as causas da sobrecarga dos Serviços de Urgência, sobretudo dos Hospitais Universitários.

As Salas de Urgência desses hospitais recebem pacientes sem encaminhamentos ou encaminhados de forma inadequada. A capacidade de acomodação, em geral, é ultrapassada e é frequiente os pacientes ocuparem os corredores em macas, cadeiras de rodas e até mesmo no chão. (Figura 8) O trabalho é caótico e os conflitos entre equipes de saúde, pacientes e familiares se transformam, com freqüência, em mediação nas Comissões de Ética, na Polícia e na Justiça.

Em outubro de 1996, o Sistema de Atendimento Médico de Urgência (SAMU) é implementado em Ribeirão Preto pela Secretaria Municipal de Saúde (Figura 9) e inicia-se a assistência médica, móvel, préhospitalar, com a tentativa de direcionar o fluxo de pacientes.

A ordenação do fluxo de pacientes para os serviços hospitalares de referência, por meio de ações do atendimento pré-hospitalar e da Regulação Médica, foi pactuada no segundo semestre de 1999, mediante entendimentos entre a UE, a Direção Regional de Saúde XVIII e a Secretaria Municipal de Saúde de Ribeirão Preto. Preliminarmente, foram mapeados os recursos assistenciais de urgência, com a definição da hierarquização, do acesso e da capacidade assistencial, oferecida pelos prestadores de serviço. $\mathrm{Na}$ época, ficou pactuado entre os gestores, os prestadores e a população que as Unidades Básicas e os Centros de Saúde passariam a ser a porta de entrada para os Serviços de Urgência. Ademais, com os recursos já existentes, organizou-se a Central Única de Regulação Médica (CURM), que assumiu a função de ordenar o fluxo de pacientes e garantir o acesso para a rede hospitalar.

A UE assumiu, perante o sistema, a referência para os cuidados aos casos mais complexos de uma região que abrange cerca de 4 milhões de pessoas. Vale lembrar que, na época, a Sala de Atendimento da UE trabalhava com uma sobrecarga flagrante na avaliação de pacientes encaminhados ou que a procuravam espontaneamente para atendimento, de forma inadequada.

Trabalhando com as orientações do SUS, mais especificamente das Portarias do Ministério da Saúde 824/99, e suas reedições (814/01 e 8720/02), a Secretaria de Estado da Saúde, a Secretaria Municipal da Saúde, o SAMU, o Corpo de Bombeiros e o HCFMRP-USP fundiram os seus recursos e suas práticas junto à CURM. Com vistas ao fortalecimento político e técnico do processo, as Universidades, a Polícia Militar, os Conselhos Regional de Medicina e Municipal de Saúde de Ribeirão Preto, o Centro de Medicina Legal, os Hospitais Filantrópicos e as Concessionárias de Autovias foram convidados a participar do processo de Gestão da CURM. Nesse momento, a Atenção às Urgências ganhava um instrumento de comunicação e assistência e, principalmente, de gestão dos seus recursos. Em janeiro do ano de 2000, os médicos reguladores e os auxiliares de comunicação passaram a operar junto à CURM, via telefone, fax e rádio, recebendo, diuturnamente, chamados de domicílios, dos logradouros públicos, dos estabelecimentos de saúde e do atendimento pré-hospitalar. A CURM (Figura 10), mediante avaliação da gravidade e da disponibilidade de recursos, passou a organizar o fluxo para os hospitais.

A equipe técnica da CURM passou a racionalizar a utilização dos recursos hospitalares, preservando os espaços aptos a atender a alta complexidade, garantindo o atendimento imediato às situações que colocam a vida em perigo iminente. Assim, pacientes que não demandam investigação e procedimentos especializados, em geral, não são mais encaminhados à UE.

Vê-se que a redução do número de encaminhamentos para a UE foi significativa, quando se cotejam os dados do ano de 1999 com os observados em 2000, 2001 e 2002. (Gráfico 1) O maior impacto das ações da CURM ocorreu com o fluxo de adultos. A redução do fluxo de crianças para a UE já estava ocorrendo progressivamente, em função da organização do SUS e do preparo dos pediatras para o cuidado integral às crianças, com ações de promoção à saúde, prevenção de doenças e tratamento curativo em todos os níveis de atenção.

A percentagem de ocupação de leitos na UE, antes das ações da Regulação Médica, eram inaceitáveis: em 1999, atingiu 113\%. Havia pacientes mal acolhidos, subavaliados e subtratados, em macas e cadeiras de roda, nos corredores do hospital. No ano de 2000, a taxa de ocupação, em média, foi de $97,1 \%$, no ano de 2001, em média, foi de $88,4 \%$ e, em 2002 , de 90,3\%. (Gráfico 2).

Todavia, as áreas de Clínica Médica e Ortopedia ainda trabalham com taxas superiores a $100 \%$ de ocupação (Gráfico 3), o que indica, para os gestores da saúde e para os dirigentes dos aparelhos formadores e administradores hospitalares, que a atenção ao idoso e à violência no trânsito precisam ser equacionadas.

A média da permanência hospitalar, após a regulação médica, aumentou, em função da maior gravi- 

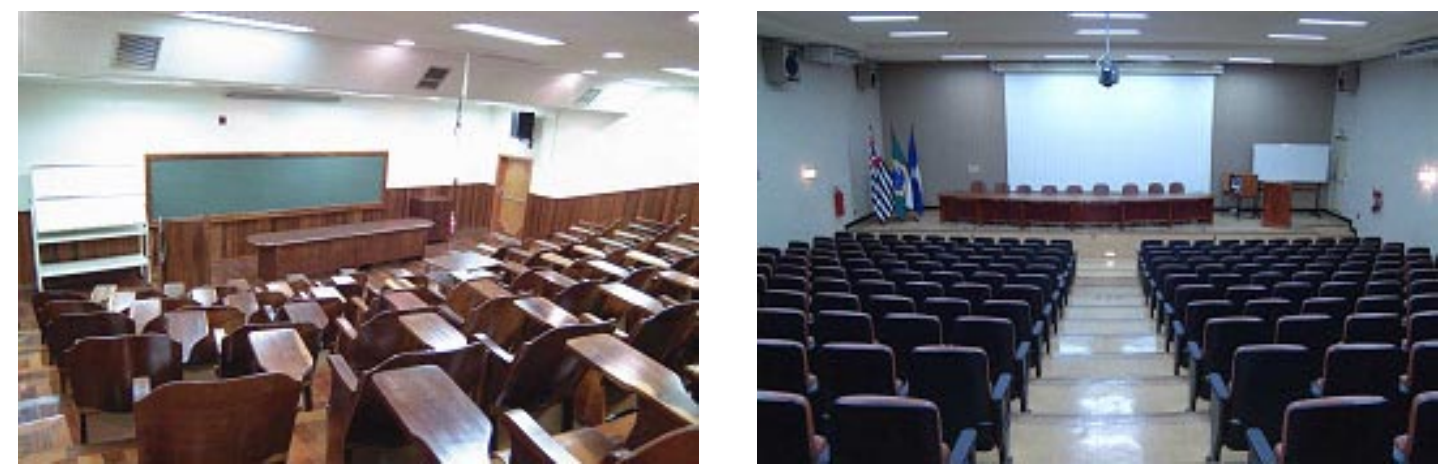

Figura 6 - (esquerda) Sala de aula. (direita) Anfiteatro Waldemar B. Pessoa.
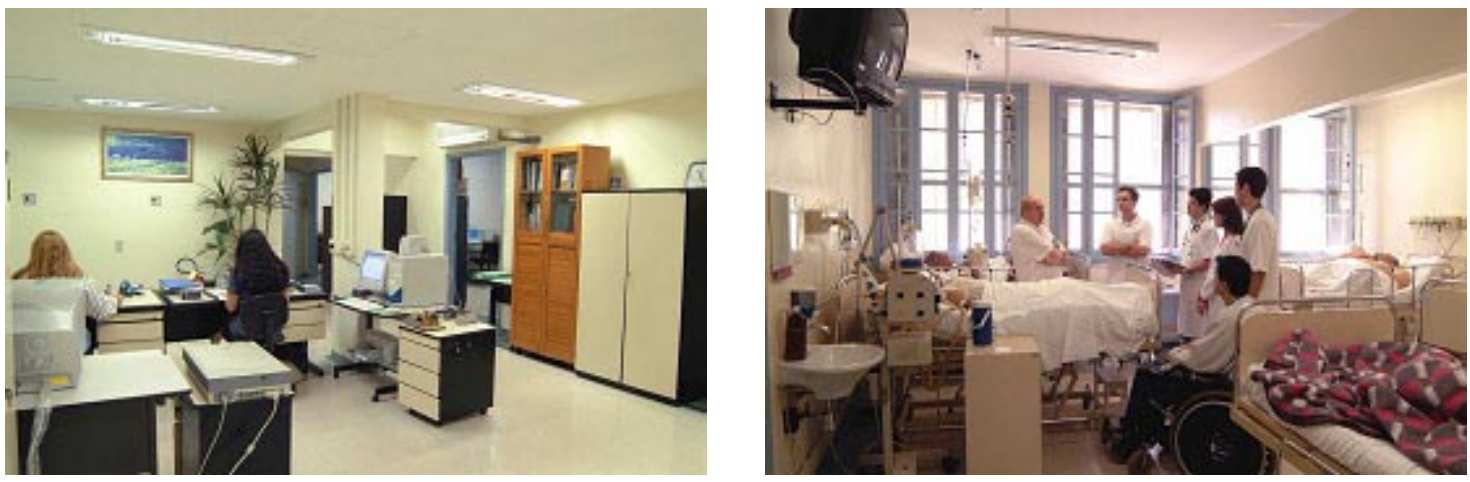

Figura 7 - (esquerda): Centro de Estudos de Emergência em Saúde. (direita): Visita coletiva à enfermaria de Clínica Médica (2002).

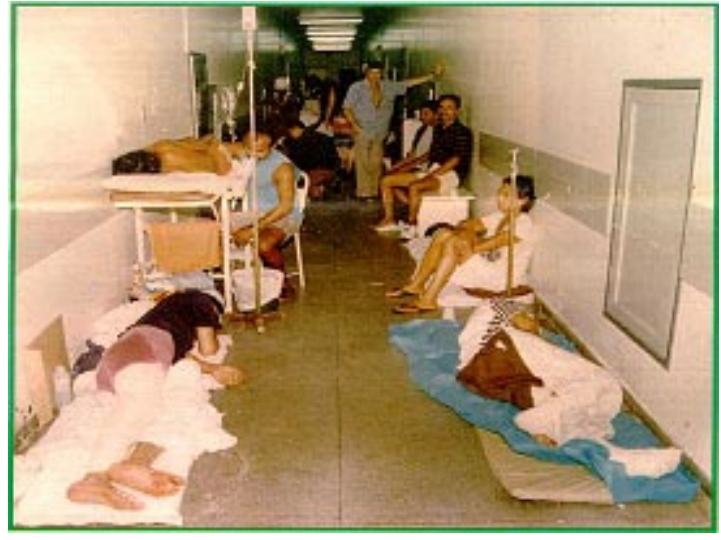

Figura 8 - Corredor de hospital, ocupado por pacientes à espera de atendimento. Reproduzida de matéria do Conselho Federal de Medicina, dezembro de 1998.

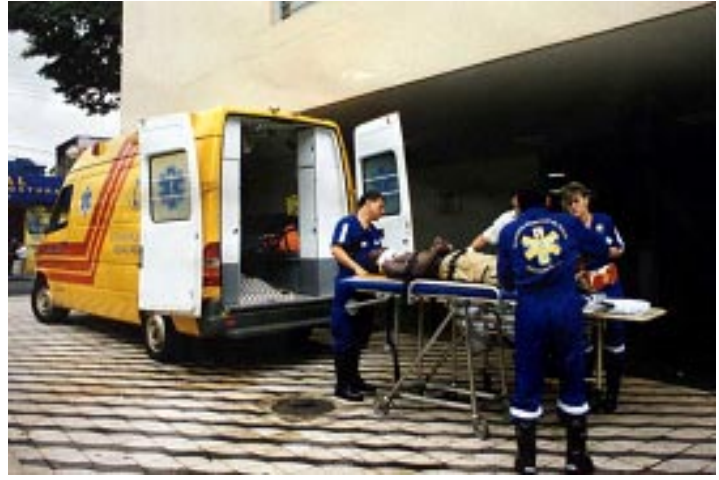

Figura 9 - Atendimento pré-hospitalar do SAMU de Ribeirão Preto.

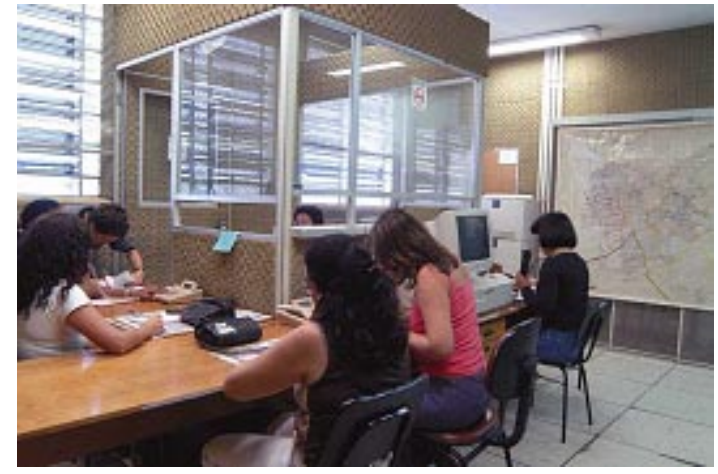

Figura 10 - Base Municipal da Central Única de Regulação Médica - Ribeirão Preto. 


\section{Consultas da Unidade de Emergência}

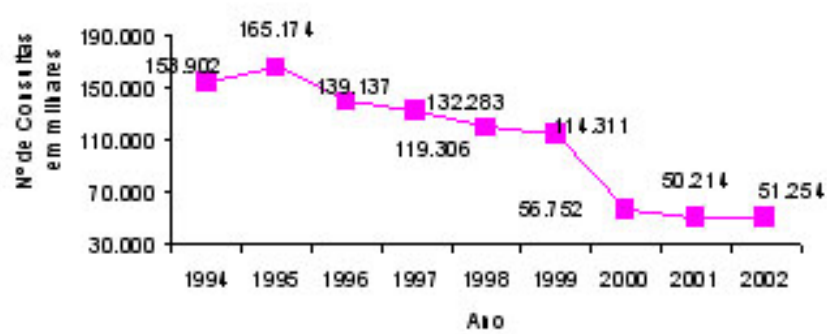

Gráfico 1 - Evolução do número de consultas na UE-HCFMRPUSP mediante início da Regulação Médica, no ano de 2000.

\section{Taxa Média de Ocupação na Unidade de Emergência}

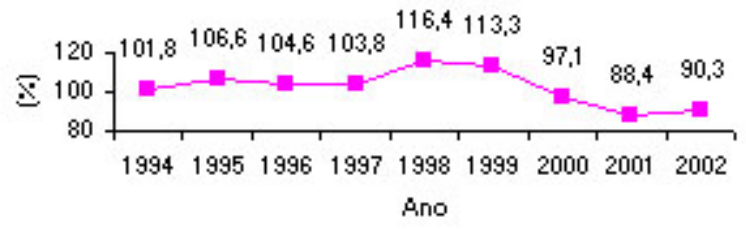

Gráfico 2 - Evolução anual da média de percentagem de ocupação de leitos na UE-HCFMRP- USP após o início da Regulação Médica no ano de 2000 .

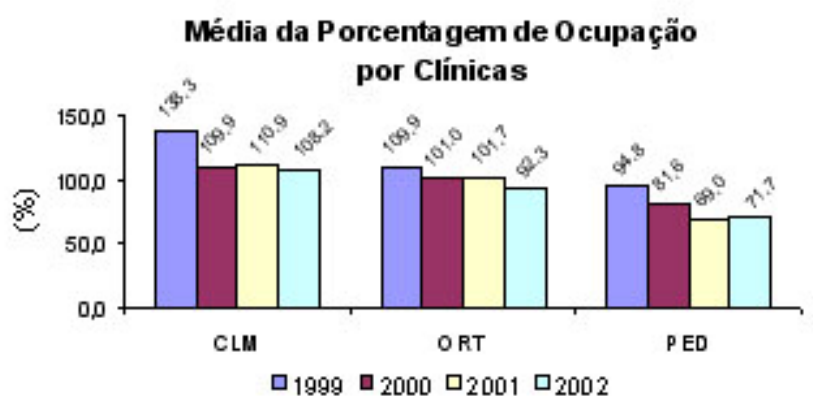

Gráfico 3 - Evolução da média da percentagem de ocupação nas diferentes clínicas da UE do HCFMRP-USP mediante início da Regulação Médica, no ano de 2000.

\section{Média de Permanência}

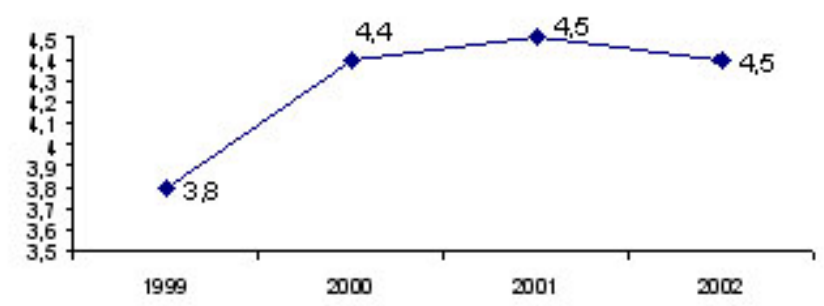

Gráfico 4 - Evolução anual da média de permanência hospitalar da UE do HCFMRP - USP mediante início da Regulação Médica, no ano de 2000. dade dos casos. (Gráfico 4) Assim, outras estratégias de assistência à saúde (programa de saúde da família, assistência domiciliar, internação domiciliar, unidades de retaguarda e reabilitação), que podem reduzir a permanência hospitalar e qualificar o processo assistencial, precisam ser implementadas ou fortalecidas.

Embora a UE esteja recebendo do SUS os casos mais complexos e ainda atue com taxas de ocupação elevadas em algumas áreas, houve redução discreta do coeficiente de mortalidade (Gráfico 5), fenômeno que coincidiu com o início das atividades da Regulação Médica e outros ajustes realizados no âmbito da Unidade de Emergência, como a ampliação de leitos para pacientes críticos.

\section{Média do Coeficiente de Mortalida de}

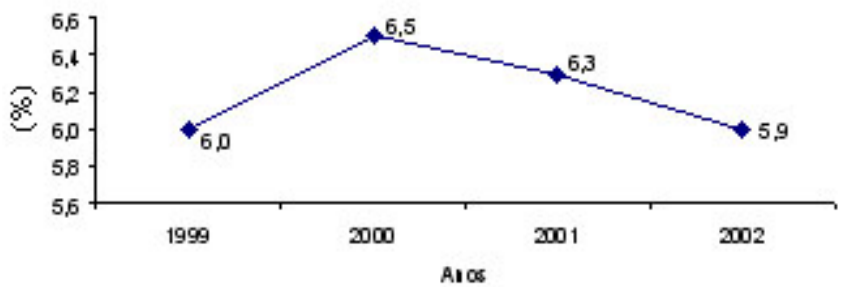

Gráfico 5 - Evolução anual da média do coeficiente de mortalidade da UE do HCFMRP- USP mediante início da Regulação Médica, no ano de 2000.

Esses ajustes contribuíram para o início, há 2 anos, do processo de humanização no atendimento de urgência na UE. Com a redução da superlotação na Sala de Urgência, foi organizado um espaço para o acolhimento dos dramas social e psicológico dos pacientes e familiares, que se deparam com agravos agudos à saúde. (Figuras 11a e 11b) As visitas aos doentes passaram a ser diárias e tiveram seus horários ampliados. Ademais, pode-se garantir, dentro das limitações estruturais da UE, o acompanhante para crianças, adolescentes, idosos, deficientes físicos e mentais e para pacientes em atendimento.

\section{PROCESSO DE HUMANIZAÇÃO}

A Unidade de Emergência do Hospital das Clínicas da Faculdade de Medicina de Ribeirão Preto USP vem implantando um programa de humanização, que se desenvolveu conjuntamente com as reformas na estrutura física, as mudanças na organização do acesso ao sistema de urgência e emergência, a instalação de um modelo de gestão compartilhada e a capacitação dos seus trabalhadores. 


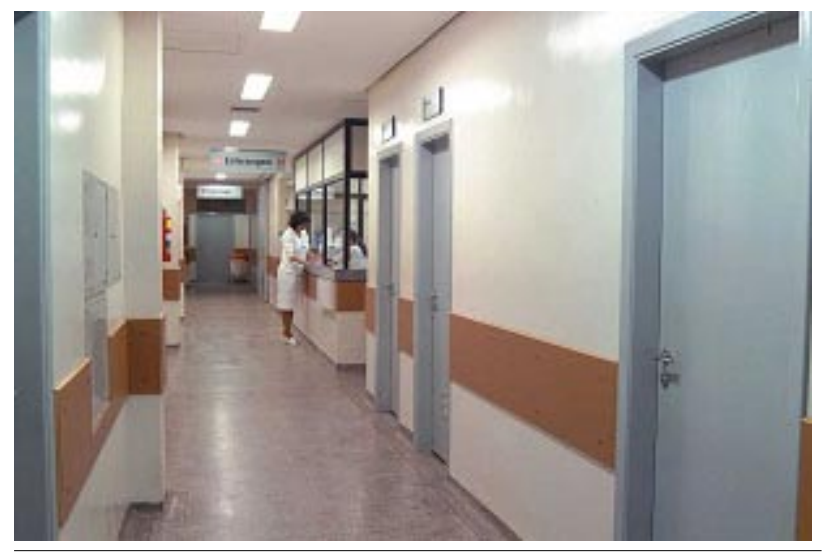

Figura $11_{\mathrm{a}}$ - Corredor da Sala de Urgência da UE após ordenação do fluxo de pacientes.

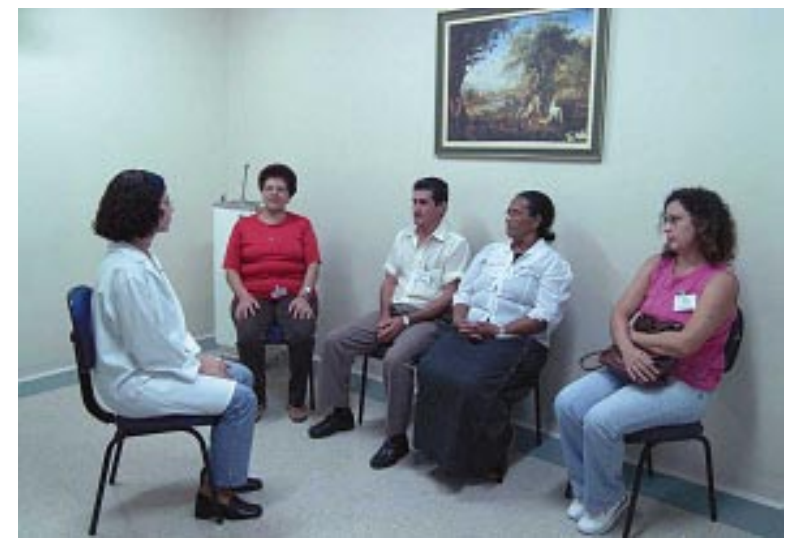

Figura $11_{\mathrm{b}}$ - Sala de acolhimento psicossocial de familiares.

As reformas na estrutura física têm garantido a melhor acomodação dos usuários, dos funcionários e a instalação de novas formas de cuidado.

Com melhores condições de atendimento às necessidades de saúde dos pacientes, foi possível pensar na criação de um espaço de acolhimento. O horário de visitas foi ampliado. Nas enfermarias, os pacientes recebem visitas das 13:00 às 21:00 h, na Sala de Urgências Clínicas e no Ambulatório de Pediatria a visita está liberada nas 24 horas, podendo cada visitante permanecer 15 minutos junto ao pacientes; nos espaços especiais (CTI, Sala de Trauma, Sala de Estabilização Clínica, Unidade de Queimados e Centro de Recuperação Pós-Anestésica) há horários específicos para visita nos 3 períodos do dia. Com isso, o paciente pode contar com o apoio familiar mais constante durante o período de hospitalização, e a comunidade passa a ter maior proximidade do trabalho das equipes de saúde.

O Serviço Social está disponível nas 24 horas, oferecendo um espaço para o acolhimento das necessidades sociais e emocionais dos pacientes e de seus familiares. As situações especiais, como óbito, violência, trauma grave recebem atenção especial com privacidade para as manifestações emocionais, procurando-se estabelecer condições para um atendimento multiprofissional, com a presença de médicos, assistentes sociais, psicólogos e enfermeiros.

A instalação de um modelo de gestão participativa, que prioriza a administração através de espaços coletivos, contribui para o processo de humanização, à medida que valoriza e garante a inclusão do profissional e do usuário no planejamento, análise, tomada de decisão e execução de projetos a serem desenvolvidos nos espaços onde estão inseridos.

Dessa forma, o funcionamento da UE passa a oferecer clareza das necessidades técnicas e administrativas e, principalmente, daquelas diretamente ligadas às relações interpessoais, tanto entre profissionais quanto entre equipe de saúde e usuários, apontando as necessidades de investimento na capacitação dos servidores, para o desempenho técnico e nas relações interpessoais.

$\mathrm{Na} \mathrm{UE}$, foram introduzidos os programas de capacitação técnica dos profissionais de saúde, destinados a médicos e enfermeiros e treinamentos específicos para os profissionais de infra-estrutura, manutenção e higiene e limpeza. Também, têm sido desenvolvidos programas com ênfase na abordagem das relações interpessoais. Para tal, foram criados grupos de psicodrama e musicoterapia, com participação voluntária, no horário de trabalho, e que tem como objetivo capacitar os profissionais para o acolhimento nas ações que envolvem o público interno e o externo.

\section{REESTRUTURAÇÃO FÍSICA E FUNCIO- NAL DA UNIDADE DE EMERGÊNCIA}

Dentre outros, 5 processos, atuando de forma convergente, exerceram influência no rearranjo físico-funcional da UE, entre os anos de 1999 e 2002.

- O ajuste das relações entre a UE e o SUS, em função da implantação do SAMU e da CURM.

- As mudanças no modelo de gestão da UE com a criação das 13 Unidades Funcionais.

- A introdução de estratégias de controle público, por meio da ampliação do horário de visitas, da flexibilização e garantia de acompanhantes para os pacientes e da implantação do Serviço de Ouvidoria.

- A motivação para capacitação técnica, gerencial e de interação grupal.

- A busca do padrão sanitário no ambiente de trabalho. 
Dessa forma, houve deslocamentos de serviços, fusões de práticas e de serviços, ampliação de alguns serviços e criação de novos serviços.

O prédio da UE com os Blocos, chamados de $A$ e $B$, passou por uma reorganização. No pavimento térreo, as áreas agregadas ao Bloco A e B foram destinadas às atividades administrativas, acadêmicas e de apoio aos trabalhadores e ao Hospital. Nos andares do Bloco A, concentraram-se as enfermarias e, no Bloco B, estão localizados alguns serviços de apoio e áreas assistenciais de acesso mais restrito para pacientes com cuidados especiais. (Tabela I)

Em linhas gerais, a administração, os serviços de apoio ao hospital e as atividades acadêmicas para grandes grupos foram deslocados da área assistencial do hospital. O pavimento térreo do Bloco A e do B passou a abrigar apenas a Sala de Urgência dos adultos. (Figura 12)

As áreas de internação para crianças que estavam no $1^{\circ}, 2^{\circ}$ e $3^{\circ}$ andares estão concentradas no $1^{\circ}$ andar. (Figura 13)

No $2^{\circ}$ andar (Bloco A), está a enfermaria para adultos com afecções clínicas e neurológicas, (Figura 14) e, no Bloco $B$, fica o isolamento e semi-intensivo.

No $3^{\circ}$ andar, (Bloco A) estão localizadas as enfermarias e o isolamento para os pacientes cirúrgicos

\begin{tabular}{|c|c|c|}
\hline \multicolumn{3}{|c|}{ Tabela I - Disposicăo dos Recursos Assistenciais da UE } \\
\hline LOCAL & FUNCÁOO & CAPACIDADE \\
\hline \multirow[t]{2}{*}{ Sala de Urgência * } & Consultórios & 8 \\
\hline & Sala de Procedimentos & 16 \\
\hline \multirow[t]{3}{*}{ Adultose Crianças } & Leitos de Observaçã̃o & 35 \\
\hline & Estabilização Clínica & 6 \\
\hline & Estabilizaçẫo de Politraumatzado & 5 \\
\hline \multirow[t]{3}{*}{ Enfermarias } & Adultos Clínicos e Neurológicos & 31 \\
\hline & Adultos Cirúrgicos & 31 \\
\hline & Crianças & 28 \\
\hline \multirow[t]{8}{*}{ Unidades Espec iais } & Terapia Intensiva de Adultos & 16 \\
\hline & Terapia Intensiva de Crianças & 6 \\
\hline & Unidade de Queimados & 8 \\
\hline & Isolamento de Crianças & 8 \\
\hline & Isolamento de Adultos & 10 \\
\hline & Semilntensivo de Adultos & 10 \\
\hline & Recuperaçẫo Pós-Anestesia & 7 \\
\hline & Psiquiatria & 6 \\
\hline TOTALDE LEITOS & & 207 \\
\hline
\end{tabular}

(Figura 15), e no Bloco B, o Centro de Terapia Intensiva e a Unidade Respiratória.

No $4^{\circ}$ andar, (Bloco A) está a Unidade de Queimados e no Bloco B estão os Centros Cirúrgico, de Recuperação Pós-Anestesia e de Terapia Intensiva. (Figura 16)

Recentemente, foi inaugurada uma área de Cultura e Lazer entre os Blocos A e B, dotada de um pátio interno no andar térreo e de um mezanino no $1^{\circ}$ andar. (Figura 17) A área tem a finalidade de abrigar atividades recreativas, destinada aos trabalhadores e pacientes. Também possibilita o apoio a pequenos encontros acadêmicos, científicos e de capacitação, bem como serve para manifestações festivas, religiosas e culturais.

Assim, nos últimos anos, a interação da UE com as políticas públicas de atenção às urgências, redefiniu sua missão e o seu paradigma de trabalho junto à sociedade.

As dúvidas existentes quanto aos reflexos das mudanças na qualidade de assistência do Hospital das Clínicas bem como no ensino da FMRP-USP foram, aos poucos, dirimidas. Os ajustes feitos no complexo Hospital das Clínicas, FMRP-USP e Unidade de Emergência têm sido testados e aprovados por meio de avaliações externas.

Nossos estudantes, por meio do Provão do Ministério da Educação, nos últimos anos, têm situado a FMRP-USP entre as 6 melhores Instituições do País. No ano de 2002, nossa Faculdade obteve o melhor desempenho nacional nessa modalidade de avaliação. (Gráficos 6 e 7)

$\mathrm{O}$ entendimento feito para a construção de uma rede assistencial, hierarquizada e regulada com o fluxo adequado à capacidade física e funcional, associado ao acolhimento do Hospital das Clínicas foram avaliados e aprovados por agentes externos e pela população. Recentemente, o Hospital das Clínicas de Ribeirão Preto, foi contemplado pelo Ministério da Saúde com o Prêmio Qualidade Hospitalar - 2001 - Categoria Nacional, (Figura 17) ficando entre os 10 melhores classificados do País, mediante avaliação de desempenho feita pelos usuários do Sistema Único de Saúde. 


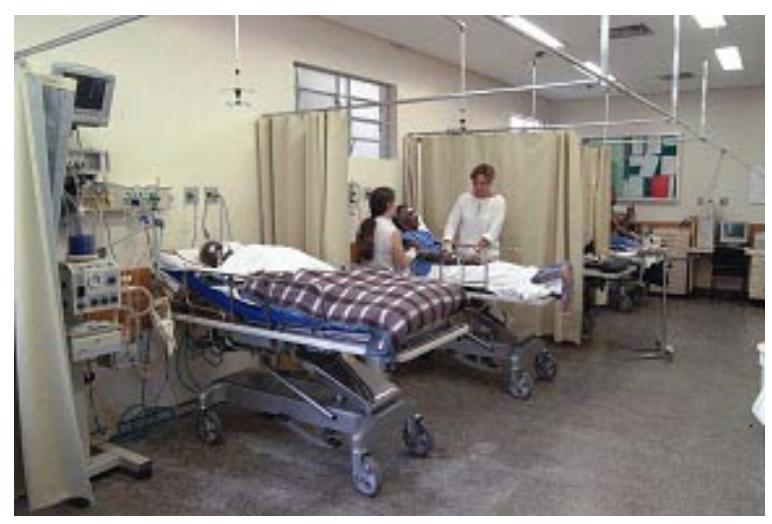

Figura 12a - Sala de Estabilização Clínica.

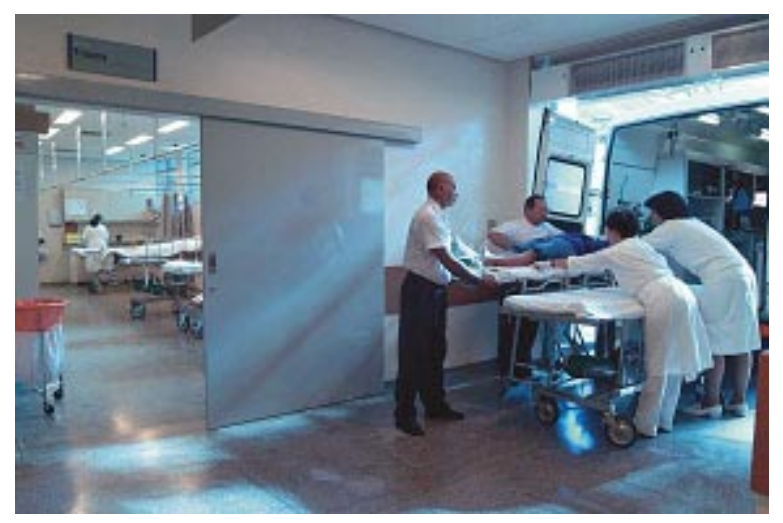

Figura $12_{\mathrm{b}}$ - Sala de Trauma.

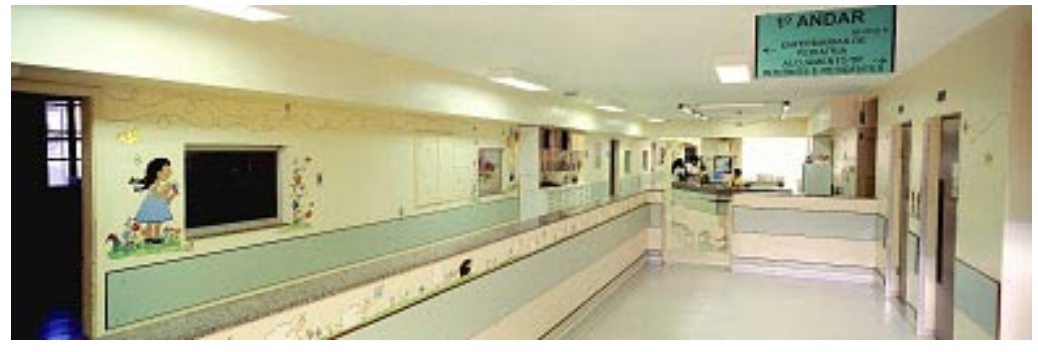

Figura 13 - Enfermaria das crianças.

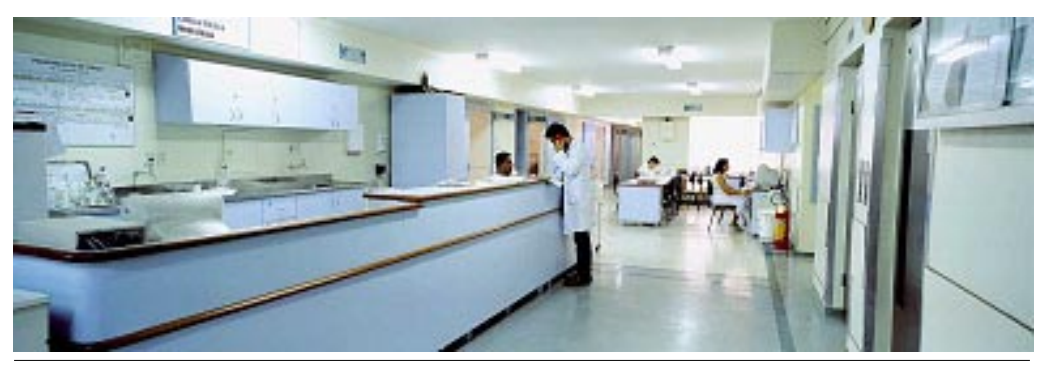

Figura 14 - Enfermaria das Clínicas Médicas e Neurológica.
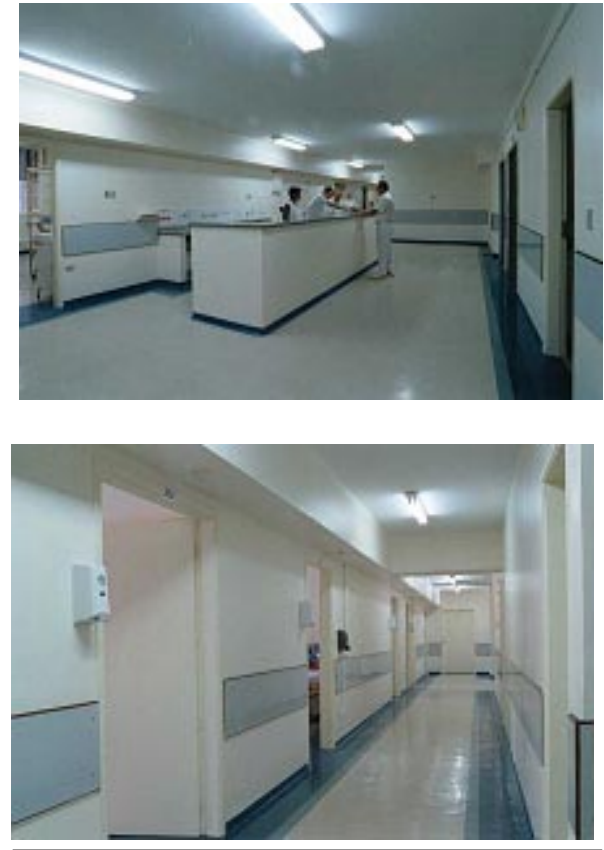

Figura 15 - Enfermaria das Clínicas Cirúrgicas

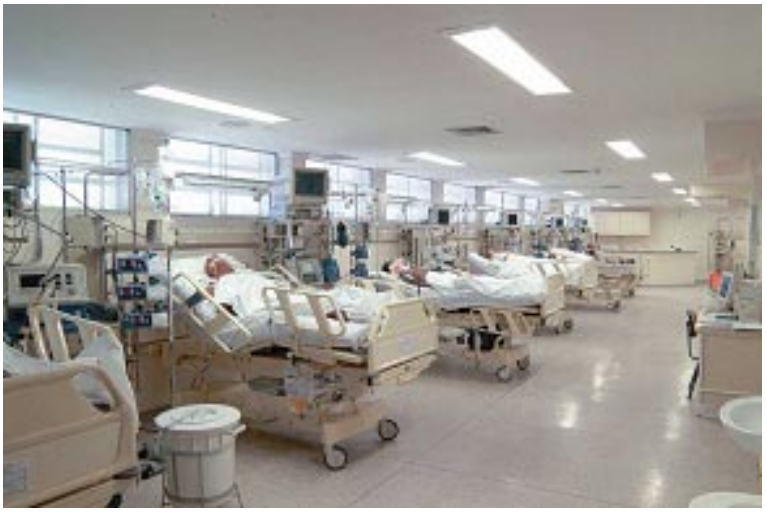

Figura 16 - Centro de Terapia Intensiva de Adultos.

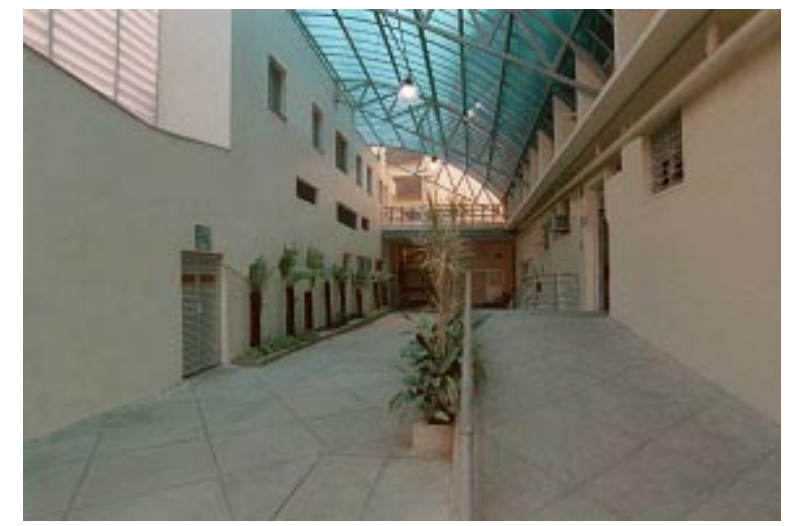

Figura 17 - Área de Cultura e Lazer. 


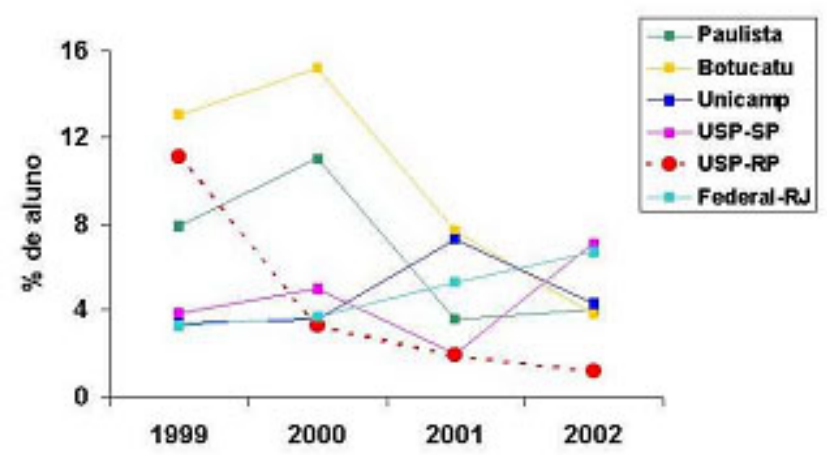

Gráfico 6 - Proporção (\%) de alunos das diferentes faculdades, situada no quartil inferior ( $25 \%$ dos piores resultados) do Provão.

No ano de 2002, o processo de organização da Rede de atenção às urgências mediante ordenação pela regulação médica e o impacto nas práticas e nos indicadores hospitalares da Unidade de Emergência por apreciado no Programa de Gestão Pública e Cidadania. Na oportunidade, dentre os 981 projetos inscritos, a Unidade de Emergência foi pre-

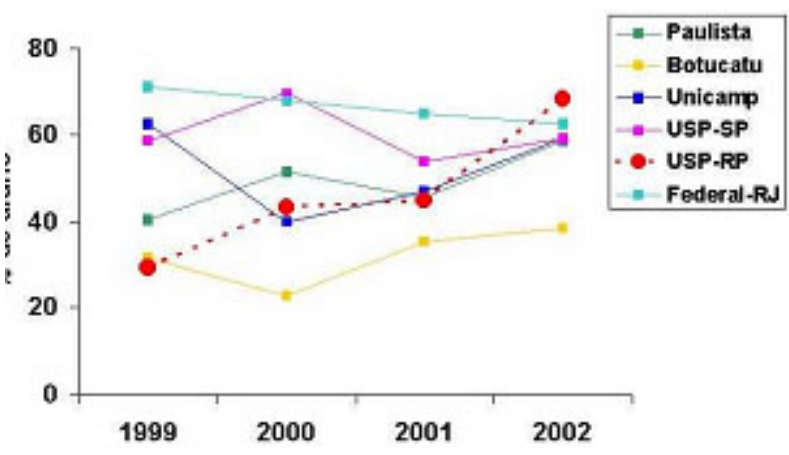

Gráfico 7 - Proporção (\%) de alunos das diferentes faculdades, situada no quartil superior ( $25 \%$ dos melhores resultados) do Provão.

miada e como semifinalista e recebeu diplomação auferida pelas fundações Getulio Vargas e Ford.

Colaboraram na elaboração deste artigo o jornalista Luiz Henrique Porto, os professores doutores: Marisa M. de Azevedo Marques, Sandro Scarpelini, Clarice A. Ferraz, a psicológa Silvia A. Tenan Magalhães e a assistente social Edna de Almeida.

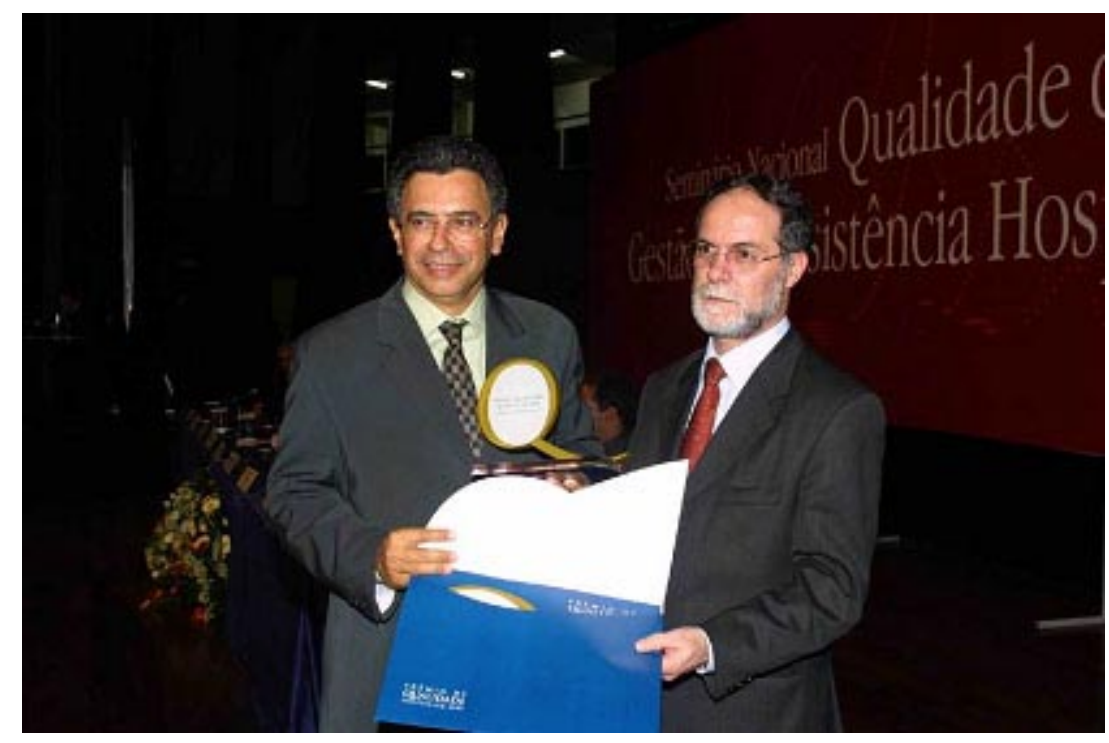

Figura 18 - Ministro da Saúde, Barjas Negri, entrega Prêmio Qualidade Hospitalar 2001 ao Superintendente do HCFMRP-USP, Prof. Dr. Marcos Felipe Silva de Sá, em 2002. 


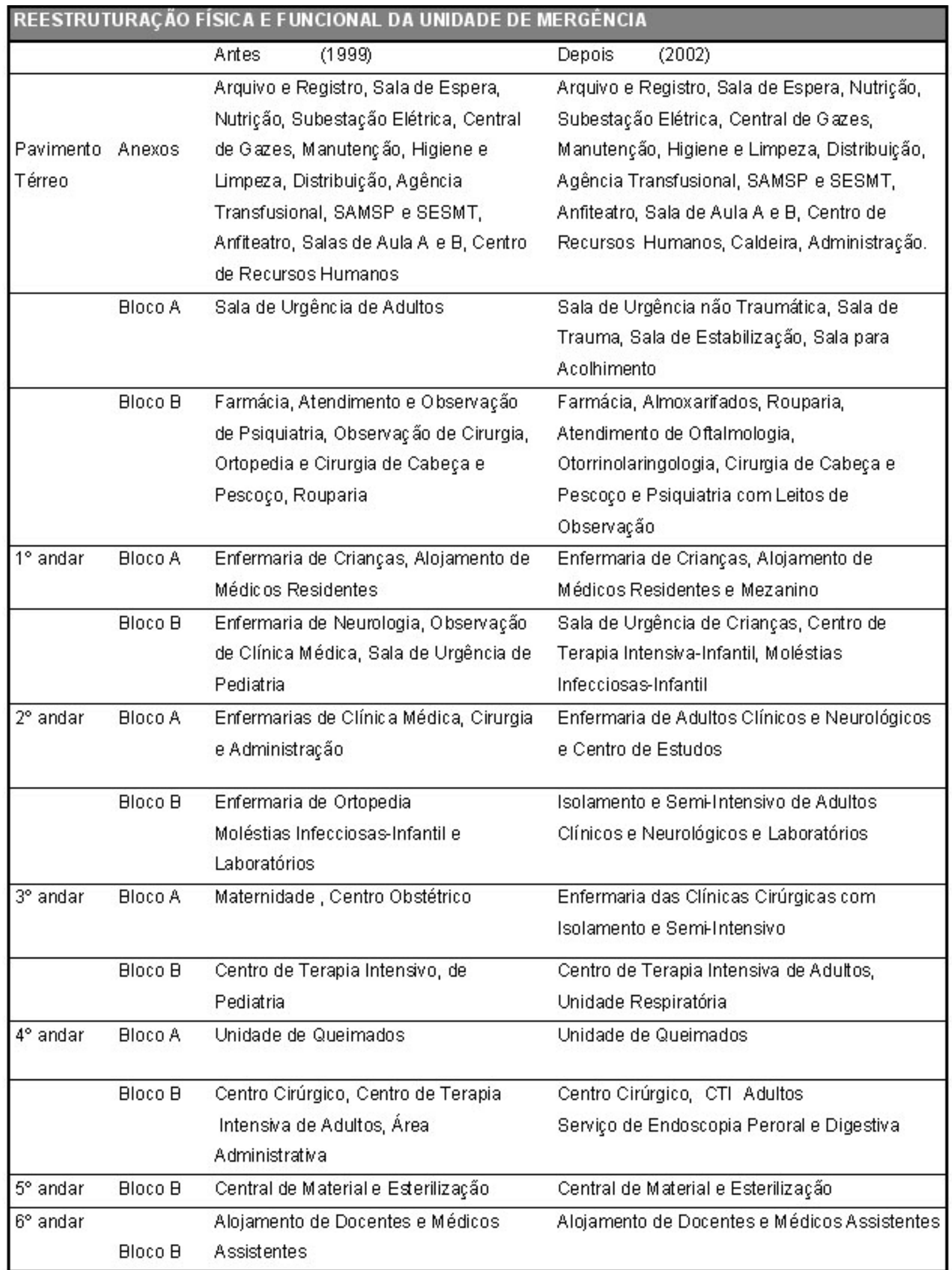

